\title{
OPINIÃO DO GRADUANDO DE ENFERMAGEM SOBRE A FORMAÇÃO DO ENFERMEIRO PARA O SUS: UMA ANÁLISE DA FAEN/UERNa
}

\author{
Opinion of the nursing graduate student on the formation of \\ nurses for sus: an analysis of FAEN/ UERN
Opinión del estudiante de enfermería sobre la formación del enfermero para el sus: un análisis de la FAEN/ UERN

\begin{abstract}
RESUMO
0 estudo objetivou identificar a opinião dos graduandos sobre seu processo de formação para o Sistema Único de Saúde - SUS. 0 objeto é a opinião dos graduandos de enfermagem sobre sua formação para o SUS. Pesquisa quantitativa, realizada com 30 discentes da Faculdade de Enfermagem - FAEN, unidade integrante da Universidade do Estado do Rio Grande do Norte - UERN. Observaram-se os aspectos éticos da Resolução 196/96 do Conselho Nacional de Saúde, incluindo a assinatura do Termo de Consentimento Livre e Esclarecido pelos discentes. Os dados foram coletados por meio de questionários, tabulados no Microsoft Excel e apresentados em tabelas. Os resultados, apesar de apontarem alguma rejeição em certos aspectos da proposta curricular, revelaram uma boa aceitação dos discentes quanto à eficiência e realização dos objetivos do Projeto PolíticoPedagógico, do perfil do egresso pretendido por esse projeto de ensino, bem como de seus aspectos organizacionais, implantados em 1996, ainda vigentes.
\end{abstract}

Palavras-chave: Enfermagem. Formação de Recursos Humanos. Educação em Enfermagem. Educação Superior.

\begin{abstract}
The study aimed to identify the opinion of graduating students on the process of training for the Single Health System - SUS. The object is the opinion of the nursing graduate students on their training for the SUS. Quantitative research, conducted with 30 students of the School of Nursing - FAEN, integrative unity of the State University of Rio Grande do Norte - UERN. It was observed the ethical aspects of Resolution 196/96 of the National Health Council, including the signing of the Free and Informed Consent Term by students. Data were collected through questionnaires, tabulated in Microsoft Excel and presented in tables. Results indicate some rejection in certain aspects of the proposed curriculum, revealing a good acceptance of students on the efficiency and achievement of the objectives of the Political and Educational Project, on the desired profile of the egress for this teaching project of, as well as its organizational aspects, established in 1996, currently in use.
\end{abstract}

Keywords: Nursing. Human Resources Formation. Education, Nursing. Education, Higher.

\section{Resumen}

El presente estudio tuvo como objetivo identificar la opinión que tienen los estudiantes sobre el proceso de formación para el Sistema Único de Salud - SUS. El objeto es registrar la opinión de los estudiantes de enfermería sobre su formación para el SUS. Investigación cuantitativa, realizada con 30 estudiantes de la Facultad de Enfermería - FAEN, unidad componente de la Universidad del Estado de Rio Grande del Norte - UERN. Se analizaron los aspectos éticos de la Resolución 196/96 del Concejo Nacional de Salud, incluyendo la firma del Término de Consentimiento Libre, con el consentimiento de los estudiantes. Los datos fueron colectados por medio de cuestionarios, tabulados en Microsoft Excel y presentados en tablas de datos. Los resultados, a pesar de reflejar algún rechazo de ciertos aspectos de la propuesta curricular, denotaron una buena aceptación de los estudiantes en relación a la eficiencia y cumplimiento de los objetivos del Proyecto Político-Pedagógico, del perfil del egresado exigido por este proyecto de enseñanza, tanto como sus aspectos organizativos, implantados en 1996, aún en vigor.

Palabras-clave: Enfermería. Formación de Recursos Humanos. Educación en Enfermería. Educación Superior.

${ }^{1}$ Enfermeira. Mestre em Enfermagem pela Universidade Federal do Rio Grande do Norte. Professora Assistente do Curso de Graduação em Enfermagem da Universidade do Estado do Rio Grande do Norte. Brasil. E-mail: robertaksc@bol.com.br, Enfermeiro. Doutor em Enfermagem. Professor Adjunto do Departamento de Enfermagem e do Programa de Pós-Graduação em Enfermagem Universidade Federal do Rio Grande do Norte. Brasil. E-mail: farnoldo@gmail.com 


\section{INTRODUCÃO}

O Sistema Único de Saúde (SUS), assegurado por instrumentos legais e constitucionais, para garantir seu processo de construção e consolidação, intenta a reorientação dos serviços e das práticas profissionais, intervindo sobre a educação dos recursos humanos em saúde.

0 reconhecimento da formação profissional como uma condição fundamental para manutenção e melhoria da qualidade na produção dos serviços em saúde recai sobre as Instituições de Ensino Superior (IES), particularmente a universidade, como um grande desafio que exige corajosa redefinição dos processos de formação e adequação dos currículos a partir dos projetos pedagógicos, cujas exigências requerem a preparação de profissionais qualificados, comprometidos em efetuar as mudanças necessárias no fortalecimento do SUS. ${ }^{1}$

A perspectiva conservadora, na formação das profissões em saúde, vem atravessando severas críticas e discussões ao longo dos anos e, consequentemente, sofrendo alterações, principalmente a partir da institucionalização da Lei de Diretrizes e Bases da Educação Nacional $(\text { LDB })^{2}$ e da regulamentação das Diretrizes Curriculares Nacionais (DCN) ${ }^{3}$. Dessa forma, reorienta a construção de modelos pedagógicos articulados às necessidades da sociedade e do SUS, como política pública de saúde vigente no Brasil. ${ }^{4}$

Particularmente na enfermagem, as transformações vêmse operando no âmbito do ensino e das práticas, provocando mudanças mais incisivas nos Projetos Político-Pedagógicos (PPP) dos cursos de graduação, sobre os currículos e cenários de aprendizagem.

$\mathrm{Na}$ Faculdade de Enfermagem (FAEN) da Universidade do Estado do Rio Grande do Norte (UERN), o PPP, implantado em 1996, ainda vigente, vislumbra a formação do enfermeiro crítico, reflexivo, comprometido com o desenvolvimento da profissão, produtor de conhecimento e capaz de intervir nos serviços de saúde, na perspectiva do SUS. A assunção desse perfil exigiu, naturalmente, mudanças no processo ensino-aprendizagem que estava sendo desenvolvido na instituição.

Nesse cenário em transformação, o discente, como um dos atores envolvidos no processo de ensino-aprendizagem e na construção coletiva dos PPPs, deixa de ser um mero coadjuvante e passa a configurar-se como transformador da sua realidade e detentor de conhecimentos que devem ser valorizados, na implementação e avaliação da proposta pedagógica.

Neste sentido, o estudo tem por objetivo identificar a opinião dos graduandos da FAEN/UERN a respeito do seu processo de formação para o Sistema Único de Saúde. 0 conhecimento acerca das exigências relacionadas à preparação do enfermeiro para o exercício da profissão oferece elementos para discussões do processo ensino-aprendizagem de enfermagem, incrementando as fontes de estudo e pesquisas no âmbito da formação de recursos humanos em saúde. Além disso, a análise do processo formativo faculta subsídios relevantes ao aprimoramento de projetos político-pedagógicos, na perspectiva da construção e reconstrução de estratégias capazes de superar os limites antepostos à construção de perfis profissionais almejados e necessários à consolidação do SUS.

\section{METODOLOGIA DO ESTUDO}

Trata-se de uma pesquisa do tipo exploratório-descritiva, com abordagem quantitativa, realizada na Faculdade de Enfermagem da Universidade do Estado do Rio Grande do Norte, localizada no Município de Mossoró, no Estado do Rio Grande do Norte.

Para Marconi e Lakatos ${ }^{5}$, os estudos exploratório-descritivos são investigações de pesquisa empírica que objetivam descrever o fenômeno em sua totalidade, podendo alcançar descrições tanto quantitativas quanto qualitativas a respeito do objeto, mediante a utilização de variáveis e procedimentos flexíveis de coleta de dados.

Por sua vez, a abordagem quantitativa se preocupa com o nível da realidade que pode ser quantificada. Essencialmente objetiva, essa forma de abordagem se caracteriza pela utilização da quantificação na coleta e no tratamento das informações por meio de técnicas estatísticas. ${ }^{6}$

0 período para a coleta de dados da pesquisa foi de novembro de 2006 a fevereiro de 2007. Neste, os discentes regularmente matriculados no curso de enfermagem da FAEN eram em número de 134 alunos distribuídos respectivamente nos períodos $2^{\circ}$ (28 alunos), $4^{\circ}$ (30 alunos), $6^{\circ}$ (30 alunos), $8^{\circ}$ (25 alunos) e $9^{\circ}$ (21 alunos concluintes). Desse universo de discentes, foi selecionada uma amostra intencional composta pela população de 46 alunos a serem pesquisados a partir do seguinte critério de inclusão: estar regulamente matriculado no oitavo e nono períodos do curso de graduação em enfermagem da FAEN, por se pressupor que, estando nos dois últimos períodos do curso, os sujeitos da pesquisa já possuiriam conhecimento suficiente sobre sua formação. Entre os sujeitos representativos da amostra selecionada, 30 discentes (19 do oitavo e 11 do nono período) participaram da pesquisa. Esse arranjo foi constituído a partir do atendimento aos critérios de acessibilidade e participação consentida, livre e esclarecida dos sujeitos no estudo.

Como instrumento de coleta de dados utilizou-se um questionário fechado, em formato de escala, contendo questões referentes a três categorias de análise: a primeira sobre os Objetivos e a Organização Didático-Pedagógica do Projeto Político-Pedagógico; a segunda, sobre o Perfil do Egresso proporcionado pelo Projeto Político-Pedagógico e, a terceira, sobre a Organização Didático-Pedagógica do Currículo. Este foi elaborado a partir das Diretrizes Curriculares de Enfermagem e do Instrumento de Avaliação dos Cursos de Graduação adotado pelo Sistema Nacional de Avaliação da Educação Superior (SINAES), por meio do Instituto Nacional de Estudos e Pesquisas Educacionais Anísio Teixeira (INEP), subordinado ao Ministério da Educação. 
0 questionário adaptado descreve nominalmente as questões afirmativas nas quais o aluno respondeu: concordo totalmente, discordo pouco, concordo pouco, discordo totalmente. Considerou-se na formatação e análise das tabelas o somatório dos percentuais das opções de resposta Concordam Totalmente (CT) e Discordo Pouco (DP) como um índice positivo, ou seja, de aceitação dos alunos em relação à questão afirmativa julgada. Da mesma forma, este artifício foi adotado para as respostas Discordo Totalmente (DT) e Concordo Pouco (CP), as quais representam um índice negativo, ou seja, de rejeição dos discentes em relação às afirmações do questionário.

Depois de coletados, os dados foram digitados em planilha eletrônica do Microsoft Excel XP, tabulados e organizados em tabelas contendo a frequência simples e absoluta dos dados. Estes foram, posteriormente, confrontados com os achados da literatura sobre o tema.

\section{APRESENTAÇÃO E DISCUSSÃO DOS RESULTADOS}

0 universo dos discentes participantes da pesquisa apresentava a seguinte caracterização: a maioria estava matriculada no oitavo período do curso (63\%), sendo que $57 \%$ eram alunos nivelados, tendo ingressado no curso em 2003; em sua quase totalidade, os discentes entrevistados eram do gênero feminino (80\%); a grande percentagem destes encontrava-se no grupo etário de 20 a 29 anos (77\%); 87\%

\section{Os objetivos e a organização didático-pedagógica do PPP}

Os discentes do curso de enfermagem da FAEN, quando questionados, concordaram que a organização didáticopedagógica do PPP contempla a construção coletiva e democrática do trabalho pedagógico, a valorização do aluno como sujeito da aprendizagem e a caracterização do professor como facilitador e mediador do processo de ensino-
Adotou-se a média de $70 \%$ como ponto de corte para a identificação do grau de aceitação e rejeição dos discentes em relação às questões afirmativas do questionário. Desse modo, vistos em separado, os percentuais de rejeição iguais ou superiores a $30 \%$ expressam uma situação que exige cuidados, e os percentuais de aceitação iguais ou superiores a $70 \%$ retratam uma situação positiva.

0 estudo tem como referencial ético a Resolução de $n^{0}$ 196/96 do Conselho Nacional de Saúde/Ministério da Saúde, tendo sido submetido ao Comitê de Ética em Pesquisa da Universidade Federal do Rio Grande do Norte (UFRN) e autorizado mediante o protocolo 105/06, com parecer de aprovação homologado em 25 de setembro de 2006. A assinatura do Termo de Consentimento Livre e Esclarecido pelos discentes precedeu a aplicação do instrumento de coleta de dados, e todos os discentes foram informados quanto aos objetivos e aos procedimentos da pesquisa, ressaltando a voluntariedade de sua participação e a garantia do anonimato.

eram solteiros e $50 \%$ referiram inserção no mercado de trabalho.

Os dados obtidos no questionário realizado com estes alunos foram organizados e analisados a partir de três categorias: 1) Os objetivos e a organização didáticopedagógica do PPP; 2) 0 perfil do egresso proporcionado pelo PPP; 3) A organização didático-pedagógica do currículo.

TABELA 1: Distribuição percentual das respostas dos discentes do Curso de Graduação em Enfermagem da FAEN, quanto aos objetivos e à organização didático-pedagógica do projeto político-pedagógico. Mossoró, fevereiro, 2007.

\begin{tabular}{|c|c|c|c|}
\hline $\begin{array}{l}\text { Objetivos e organização didático-pedagógica do } \\
\text { projeto politico-pedagógico }\end{array}$ & Aceitação & Rejeição & TOTAL \\
\hline $\begin{array}{l}\text { 1. Construido coletivamente, centrado no aluno } \\
\text { como sujeito da aprendizagem e apoiado no } \\
\text { professor como facilitador e mediador do processo } \\
\text { de ensino-aprendizagem. }\end{array}$ & $76 \%$ & $24 \%$ & $100 \%$ \\
\hline $\begin{array}{l}\text { 2. O PPP do curso objetiva a formação integral e } \\
\text { adequada do estudante por meio de uma } \\
\text { articulação entre o ensino, a pesquisa e a } \\
\text { extensão/assistência. }\end{array}$ & $53 \%$ & $47 \%$ & $100 \%$ \\
\hline $\begin{array}{l}\text { 3. O PPP objetiva a formação do enfermeiro } \\
\text { crítico, reflexivo para atender as necessidades } \\
\text { sociais da saúde, com ênfase no Sistema Único de } \\
\text { Saúde (SUS) e para assegurar a integralidade da } \\
\text { atenção e qualidade e humanização do } \\
\text { atendimento. }\end{array}$ & $77 \%$ & $23 \%$ & $100 \%$ \\
\hline
\end{tabular}

Fonte: FAEN/UERN. Mossoró-RN. 
A este respeito, alguns estudos vêm demonstrando a ocorrência de mudanças nas estruturas acadêmicas e nas práticas pedagógicas, favorecendo a participação do aluno como sujeito ativo da aprendizagem e o professor como um agente mediador, mais reflexivo e menos autoritário e transmissor do saber. $^{8-9}$

Desse modo, ao contemplar e articular estas práticas pedagógicas, a racionalidade na formação do enfermeiro sugere estruturalmente que os cursos de graduação assegurem também a articulação entre o ensino, a pesquisa e a extensão, de forma integrada e interdisciplinar, como forma de preparar o egresso de enfermagem com o perfil adequado e necessário à assistência à saúde, à produção do conhecimento, à formação da força de trabalho em enfermagem e à participação cidadã no atendimento às demandas da população. ${ }^{3}$

Nessa perspectiva, quanto ao objetivo do PPP, no que diz respeito à formação integral e adequada do estudante por uma articulação entre o ensino, a pesquisa e a extensão/assistência, $37 \%$ dos discentes responderam que concordam pouco e 10\% discordam totalmente, totalizando $47 \%$ de rejeição à questão.

Este dado pode encerrar outras questões que, deliberadamente, não foram contempladas nessa pesquisa, as quais recomendam estudos e análise posteriores. Dos dados apreendidos, infere-se que, ao adotar este posicionamento, eles podem estar se referindo às dificuldades, aos interesses $\mathrm{e}$ expectativas envolvidos em todo o seu processo ensinoaprendizagem, independente do que é preconizado pelo PPP.

Quando do julgamento da afirmação: 0 projeto pedagógico do curso objetiva a formação do enfermeiro crítico, reflexivo, para atender às necessidades sociais da saúde, com ênfase no

\section{O perfil do egresso proporcionado pelo PPP}

As Diretrizes Curriculares Nacionais para a Graduação em Enfermagem, em seu artigo $3^{\circ}$, estabelecem, para o formando em enfermagem, a construção de um perfil generalista, humanista, crítico, reflexivo, ético, qualificado para o exercício da profissão. E, ainda, de um profissional capaz de agir com responsabilidade social e compromisso com a cidadania, além de promover a integralidade em saúde. ${ }^{3}$

Para alguns discentes, a obtenção desse leque de características profissionais ao longo do curso é afetada pela
SUS e para assegurar a integralidade da atenção e a qualidade e humanização do atendimento, $77 \%$ dos discentes responderam positivamente, caracterizando uma aceitação relacionada ao objetivo do PPP do curso de enfermagem da FAEN.

Resultados semelhantes foram encontrados em pesquisas voltadas ao estudo de mudanças durante a formação, que procuravam a adequação a exigências para a construção de novos perfis profissionais. ${ }^{9}$ De fato, mudanças nas estruturas acadêmicas viabilizam a construção dos projetos políitcopedagógicos inovadores, considerando o estudante como sujeito ativo, crítico, questionador e inovador no processo ensinoaprendizagem, em consonância com as diretrizes para a educação de enfermagem definidas pelo Ministério da Educação. Nesse sentido, a busca por parte das Instituições de Ensino Superior, da preparação de estudantes com perfil reflexivo, ético, político, conhecedor dos determinantes históricos e culturais da profissão impulsiona e repercute positivamente na formação de futuros profissionais generalistas, politicamente participativos e com maior inserção social.

Sabe-se que os PPPs dos cursos de graduação na área da saúde devem contemplar a divulgação e a reflexão crítica do SUS e seus princípios, para que os profissionais ou egressos possam colaborar com a construção de um sistema justo, digno, solidário, resolutivo, atendendo à integralidade, à qualidade e à humanização do atendimento. Essa incorporação do SUS no processo formativo dos enfermeiros deve-se dar de forma transdisciplinar, "possibilitando maiores vivências práticas e desafiando os acadêmicos e docentes para a reflexão crítica"10:619.

fragilidade da integralidade do processo educativo, da articulação teoria-prática e da integração curricular, o que causa a construção de apenas algumas habilidades e competências essenciais, constitutivas do corpo da profissão.

Desse modo, em relação ao questionamento sobre a capacidade do formando de enfermagem em identificar as necessidades coletivas e individuais da população e seus determinantes, $80 \%$ dos discentes responderam positivamente à questão, concordando com a afirmação (Tabela 2). 
TABELA 2: Distribuição percentual das respostas dos discentes sobre o perfil do egresso proporcionado pelo projeto político pedagógico do Curso de Graduação em Enfermagem/FAEN-UERN. Mossoró/RN, fevereiro, 2007.

\begin{tabular}{|c|c|c|c|}
\hline $\begin{array}{l}\text { Perfil do egresso proporcionado pelo PPP do Curso de } \\
\text { Graduação em Enfermagem/FAEN-UERN }\end{array}$ & Aceitação & Rejeição & TOTAL \\
\hline $\begin{array}{l}\text { 1. Formando capaz de identificar as necessidades coletivas e } \\
\text { individuais da populaçăo e seus determinantes. }\end{array}$ & $80 \%$ & $20 \%$ & $100 \%$ \\
\hline $\begin{array}{l}\text { 2. Formando capaz de intervir na produção dos serviços de } \\
\text { saúde com vistas à transformaçăo dos perfis epidemiológicos ao } \\
\text { aperfeiçoamento do processo saúde-doença. }\end{array}$ & $70 \%$ & $30 \%$ & $100 \%$ \\
\hline $\begin{array}{l}\text { 3. Formando desenvolve, participa e aplica formas de produçào } \\
\text { do conhecimento visando à qualificação da prática profissional. }\end{array}$ & $61 \%$ & $39 \%$ & $100 \%$ \\
\hline $\begin{array}{l}\text { 4. Formando coordenador do trabalho de enfermagem, por meio } \\
\text { dos processos de trabalho de enfermagem (gerenciar, } \\
\text { assistirintervir, ensinar/aprender, pesquisar), nos modelos } \\
\text { clinicos e epidemiológicos de produção dos serviços de saúde. }\end{array}$ & $64 \%$ & $36 \%$ & $100 \%$ \\
\hline $\begin{array}{l}\text { 5. Formando capaz de compreender a politica de saúde no } \\
\text { contexto das politicas sociais, reconhecendo os perfis } \\
\text { epidemiológicos das populaçひes. }\end{array}$ & $53 \%$ & $47 \%$ & $100 \%$ \\
\hline $\begin{array}{l}\text { 6. Formando articulador, negociador, capaz de estabelecer } \\
\text { alianças e parcerias. }\end{array}$ & $69 \%$ & $31 \%$ & $100 \%$ \\
\hline
\end{tabular}

Fonte: FAEN/UERN. Mossoró-RN.

0 atendimento à complexidade dos problemas de saúde das pessoas exige do profissional um arsenal de tecnologias e saberes que precisam ser adquiridos ainda durante a formação acadêmica, pois são esses diferentes meios e instrumentos de trabalho que fornecerão aos futuros profissionais a capacidade de identificar os problemas e as demandas individuais e coletivas dos usuários, indispensáveis à prestação da atenção integral e humanizada às pessoas. ${ }^{11}$

A formação que adota a perspectiva da contextualização e da escuta das necessidades de saúde também assegura ao aluno a capacidade de problematizar e de descobrir as soluções criativas e cooperativas para os problemas reais, permitindo a construção do saber e da autonomia, com a intervenção do profissional de saúde na reorientação do modelo assistencial. ${ }^{12}$

Com relação à capacidade de intervir na produção dos serviços de saúde com vistas à transformação dos perfis epidemiológicos e ao aperfeiçoamento do processo saúdedoença, $70 \%$ dos discentes aceitam que essa é uma característica do perfil do egresso proporcionado pelo PPP/ FAEN.

Essa capacidade de intervenção do enfermeiro pressupõe a utilização da atividade de pesquisa e produção do conhecimento para o alcance da formação de qualidade. A atividade de pesquisa científica nos cursos de graduação em enfermagem, instrumentaliza o aluno na resolução dos problemas, permite 0 desenvolvimento da criatividade e a continuidade dos estudos, embasando-o na tomada de decisões administrativas e clínicas e incentivando-o a prosseguir com sua formação acadêmica e aperfeiçoamento cultural. ${ }^{13-14}$ Os resultados sobre 0 envolvimento do formando nas atividades de produção do conhecimento, visando à qualificação da prática profissional, mostraram $61 \%$ de aceitação e $39 \%$ de rejeição. Tal situação não atinge a média aceitável de $70 \%$ da aprovação dos discentes, revelando que ainda é necessário mais espaço, estímulo e suporte na prática educacional para a produção do conhecimento, ou seja, para a pesquisa.

Com relação à afirmativa que diz respeito à construção, possibilitada a partir do Curso de Enfermagem da FAEN, das competências e habilidades requeridas para o formando atuar como coordenador do processo de trabalho em enfermagem, no qual irá gerenciar, assistir/intervir, ensinar/aprender, pesquisar, dentre outros, nos modelos clínicos e epidemiológicos de produção dos serviços de saúde, $64 \%$ dos alunos aceitamna e $36 \%$ a rejeitam, não alcançando novamente a média aceitável de $70 \%$.

Estes resultados indicam, primeiro, a persistente dicotomia entre a formação e a prática e, segundo, a provável crise de identidade profissional, na qual prevalece uma maior fundamentação, durante a formação profissional, para os enfermeiros atuarem em determinados campos específicos, com prejuízo da integralidade formativa. ${ }^{15}$

Uma característica importante observada sobre o perfil do egresso de enfermagem diz respeito à capacidade de reconhecer as formas de organização diante da política social. Dentro desse contexto maior, o enfermeiro deve compreender as políticas de saúde, suas transformações e expressões como indicadores que interferem nos perfis epidemiológicos da população, devendo também ter consciência de ser um sujeito inserido no mesmo contexto sociocultural.

No entanto, ao se posicionarem sobre a capacidade do formando de compreender a política de saúde no contexto das políticas sociais, reconhecendo os perfis epidemiológicos das 
populações como característica do seu perfil como egresso proporcionada pelo PPP/FAEN, $47 \%$ dos discentes rejeitaram a afirmativa, contrastando com $53 \%$ dos que aceitaram.

Os resultados negativos obtidos assemelham-se a outros já encontrados. Constata-se que muitos dos enfermeiros desconhecem as políticas de saúde e o SUS como eixos norteadores das ações de atenção à saúde da população. ${ }^{10}$

Outra característica importante conferida ao perfil do egresso de enfermagem diz respeito à capacidade de articular, negociar, estabelecer parcerias e alianças no processo de trabalho em serviços de saúde. 0 conhecimento acerca dessa característica obteve como resultado $69 \%$ de aceitação dos alunos, sendo que $31 \%$ dos discentes manifestaram sentimentos de insegurança, falta de habilidade prática para negociar e articular, com prejuízos no desempenho da autonomia profissional e na mediação nas relações envolvendo o serviço, a equipe e os usuários.

Infere-se que essa realidade, revelada pelos índices de rejeição, reflete uma certa fragilidade na base do fazer dos processos educativos pouco entendidos, aderidos e assimilados na construção das competências relacionadas à prática gerencial e administrativa, ou simplesmente, na coordenação do processo de trabalho. Também reflete a necessidade de resolver problemas, situações em vigilância à saúde no estabelecimento das parcerias com sujeitos, instâncias e setores envolvidos neste trabalho.

\section{A organização didático-pedagógica do currículo}

$\mathrm{Na}$ graduação em enfermagem, particularmente, a preocupação se volta para um currículo cuja organização didático-pedagógica contemple a superação do modelo tradicional da formação biologicista, sustentando mudanças no processo educativo, rompendo com a dicotomia entre teoriaprática-serviços de saúde, proporcionando uma aprendizagem significativa em uma perspectiva pró-ativa.

0 currículo no contexto das diretrizes curriculares dos cursos de graduaçãa ${ }^{3}$ contempla os princípios organizativos e operacionais necessários à construção de um perfil acadêmico e profissional do egresso generalista, crítico e reflexivo, a partir das demandas e expectativas de desenvolvimento do setor saúde locorregional e do país.

0 ensino superior de enfermagem atravessou, desde a sua institucionalização, grandes mudanças curriculares sem, no entanto, promover mudanças expressivas nas práticas profissionais em saúde, uma vez que a atividade docente não acompanhou os pressupostos filosóficos e metodológicos de superação da pedagogia tradicional que perpetua o modelo biomédico-tecnicista na prática do enfermeiro e nos serviços de saúde. ${ }^{16}$

Sobre se o currículo, como proponente do aperfeiçoamento do modelo tradicional de ensino, aponta mudanças na prática profissional e evidencia a ocorrência de transformações no ensino desenvolvido pela instituição, permitindo a construção de um novo perfil para o profissional enfermeiro, os discentes responderam afirmativamente com 70\% de aceitação e 30\% de rejeição (Tabela 3).

TABELA 3: Distribuição percentual das respostas dos discentes sobre a organização didático-pedagógica do currículo do Curso de Graduação em Enfermagem/FAEN-UERN. Mossoró/RN, fevereiro, 2007.

\begin{tabular}{lccc}
\hline \multicolumn{1}{c}{ Organização didático-pedagógica do currículo } & Aceitação & Rejeição & TOTAL \\
\hline $\begin{array}{l}\text { 1. Propde o aperfeiçoamento do modelo tradicional de ensino, } \\
\text { apontando mudanças na prática profissional. }\end{array}$ & $70 \%$ & $30 \%$ & $100 \%$ \\
$\begin{array}{l}\text { 2.Valoriza as dimensôes éticas e humanistas, desenvolvendo no } \\
\text { aluno valores orientados para a cidadania e solidariedade. }\end{array}$ & $60 \%$ & $40 \%$ & $100 \%$ \\
$\begin{array}{l}\text { 3. Interdisciplinaridade (integração das matérias fundamentais x } \\
\text { profissionais). }\end{array}$ & $66 \%$ & $34 \%$ & $100 \%$ \\
$\begin{array}{l}\text { 4.Carga horária bem dimensionada entre as unidades de estudo. } \\
\text { 5. Estágio supervisionado no final do curso nas diversas modalidades } \\
\text { dos serviços de saúde e na comunidade. }\end{array}$ & $50 \%$ & $50 \%$ & $100 \%$ \\
\hline $\begin{array}{l}\text { 6.Contempla atividades complementares para a produção de } \\
\text { conhecimento pelo aluno (monitoria e estágios multidisciplinares, } \\
\text { programas de iniciação cientifica, extensio). }\end{array}$ & $73 \%$ & $27 \%$ & $100 \%$ \\
\hline
\end{tabular}

Fonte: FAEN/UERN. Mossoró-RN

0 modelo pedagógico tradicional, para alguns autores ${ }^{8-9}$, ainda é marcante nas instituições de ensino superior. Apesar dos esforços visualizados na consolidação de novas exigências para a formação em enfermagem, o processo de superação é tímido, com fragilidade na base teórica, na experiência docente e nos processos didáticos, comprometendo nitidamente a operação das mudanças estratégicas nos processos, nos cenários de formação e na prática profissional do enfermeiro.

Adicionem-se a isto as posturas conservadoras, quer dos docentes, quer dos discentes sobre o modelo pedagógico, à 
medida que consideram a valorização e a exclusividade da competência técnica-profissional na preparação dos profissionais de enfermagem ${ }^{17}$, ou seja, a técnica pela técnica em detrimento do conjunto das competências na construção do perfil de egressos.

0 currículo do curso de enfermagem, para os discentes da FAEN, no que diz respeito à sua organização didáticopedagógica, levando em conta o ponto de corte, não valoriza suficientemente as dimensões éticas e humanistas, comprometendo o desenvolvendo no aluno de valores orientados para a cidadania e solidariedade ( $60 \%$ de aceitação e $40 \%$ de rejeição).

Muitas questões poderiam ser levantadas a este respeito, uma, porém, atinge o problema centralmente: os conteúdos sobre ética estão centrados em uma única disciplina ou será que os alunos não conseguiram vislumbrar os preceitos éticos em todo o transcurso do currículo?

De fato, a análise do PPP/FAEN e a distribuição dos conteúdos relacionados com esta dimensão formativa, não contemplada diretamente neste estudo, não leva a concluir sobre a existência de concentrações de conteúdos éticos e humanísticos em uma ou outra disciplina, levando à falta de transversalidade destas temáticas. 0 problema pode está centrado, por outro lado, nas dificuldades de concretização das propostas do PPP ou mesmo na disposição negativa em assumir, por parte dos envolvidos no processo formativo, inclusive discentes, critérios de valores éticos adequados, ademais, nem sempre compartilhados.

Assim, estes resultados também remetem a este indicador importante da organização didático-pedagógica do currículo que é a interdisciplinaridade, como prática fundamental que induz a necessidade do diálogo interdisciplinar entre conteúdos e eixos temáticos, em contraposição à tradicional matéria ou disciplina, no estabelecimento do modelo pedagógico com todos os atores envolvidos.

A integração interdisciplinar é, na FAEN, como na maioria das instituições de ensino da área de saúde, uma prática realizada pela maioria dos docentes, embora essa operacionalização seja, na maioria das vezes, ineficaz, por se encontrar limitada ao compartilhamento de conhecimentos específicos, a depender, geralmente, da própria iniciativa docente, do planejamento e da condução da disciplina. ${ }^{18}$

Ainda quanto à interdisciplinaridade, no que concerne à integração entre os conteúdos disciplinares das áreas fundamentais e aqueles das áreas profissionais no currículo do curso de enfermagem da FAEN, 66\% dos discentes participantes do estudo opinaram pela sua eficiência, embora $34 \%$ a tenham rejeitado.

Nos currículos dos cursos da área da saúde, entre eles o de enfermagem, e, neste estudo particular, o da FAEN, ainda é possível visualizar a relação assimétrica entre as disciplinas do tipo fechada, com conteúdos delimitados em relação vertical, sendo a pré-requisitação um recurso continuamente utilizado como forma de viabilizar a interdisciplinaridade. ${ }^{16}$ Como agravante, em muitos casos, a estrutura curricular também apresenta um mau dimensionamento entre as unidades de estudo, bem como um descompasso entre as disciplinas da área clínica/individual e da área epidemiológica/coletiva, esta quase sempre respondendo por uma carga horária relativamente inferior.

Uma outra questão de grande significado e impacto diz respeito à distribuição das unidades de estudo curriculares. Os pressupostos do modelo de formação biomédico e hospitalocêntrico privilegiam a performance profissional para atuar na atenção à saúde curativa e individual. Outros modelos, contrapostos a este, entretanto, tenderam a destinar uma extensa carga horária para as disciplinas da área de saúde coletiva, contribuindo, assim, para o fortalecimento da formação crítica do aluno em relação aos problemas político-sociais, em detrimento, todavia, da construção de habilidades técnicas e instrumentais necessárias ao desenvolvimento da prática de enfermagem. 0 ideal seria uma distribuição mais harmônica dos currículos formativos, procurando contemplar tanto a formação crítica quanto a técnica do aluno.

Sobre a eficiência da carga horária e do dimensionamento entre as unidades de estudo do PPP da FAEN, um dos indicadores da organização didático-pedagógica do currículo, 50\% dos discentes demonstraram rejeição, ao contrário de $50 \%$, que concordaram com sua disposição.

Ainda, na formação do enfermeiro, de uma maneira geral, a construção de habilidades práticas, associadas aos conhecimentos teóricos adquiridos durante o curso de graduação, deve preparar o aluno para o contato com a dinâmica da realidade social e da produção dos serviços de saúde. Esse contato, entre as atividades e conteúdos práticos, é preconizado pela DCN, devendo iniciar-se o mais precocemente possível, por meio de inserções de atividades práticas curriculares, prolongando-se até aos estágios supervisionados, contemplados nos dois períodos finais do curso de graduação. Idealmente os estágios deveriam acontecer em todos os espaços de produção dos serviços de saúde, tais como hospitais gerais e especializados, rede básica de saúde e comunidade, assegurando a articulação ensino-trabalho e experiências de aprendizado, no âmbito do SUS.

Desse modo, entende-se que os cursos de graduação na área da saúde precisam recorrer, sempre que necessário e em todo o transcurso do processo ensino-aprendizagem, à rede de serviços de saúde para suas atividades práticas e estágios, como forma de ampliar as experiências e oportunidades de aprendizagem na formação geral do aluno. ${ }^{10-11}$

Nesse sentido, o reconhecimento dos discentes da FAEN sobre a questão que afirmava "o estágio supervisionado apresenta terminalidade e é facultado nas diversas modalidades dos serviços de saúde e na comunidade", obteve $73 \%$ de aceitação, contra $27 \%$ de rejeição.

Quando questionados se o currículo da FAEN contempla as atividades complementares, como indutoras da produção de conhecimentos pelo aluno (monitoria e estágios multidisciplinares, programas de iniciação científica e extensão), os discentes demonstraram índice negativo de 33\%, embora a aceitação tenha sido de $67 \%$.

0 conjunto desses resultados, que reflete o conhecimento dos discentes sobre o seu processo ensino-aprendizagem, permite a configuração de uma imagem aproximativa da 
articulação do curso de graduação em enfermagem da FAEN com os aspectos e exigências relacionados às recentes políticas públicas para o SUS e à educação, expressa na Lei de Diretrizes e Bases da Educação Nacional ${ }^{2}$ e nas Diretrizes Curriculares para os Cursos de Graduação em Enfermagem³ . Deste modo,

\section{CONCLUSÕES}

No âmbito da enfermagem, a busca por um profissional com formação generalista, na construção de competência e habilidades, quer acadêmico-científicas, quer éticohumanísticas, de acordo com as exigências do SUS, é um compromisso assumido e pactuado pela profissão. Neste sentido, atualmente os PPPs procuram ser, nas instituições de ensino superior de enfermagem, instrumentos que contribuem para a construção coletiva de processos formativos capazes de responder a esta demanda.

Em relação ao curso de graduação em enfermagem da FAEN/UERN, a partir das intenções do PPP/1996, na opinião dos alunos, a operacionalização da proposta pedagógica do curso apresenta pontos vulneráveis, como os que fazem referência à valorização da dimensão ética e humanística ( $40 \%$ de rejeição), pouco contemplada de modo direto no currículo e, certamente, interdisciplinarmente, uma vez que há $34 \%$ de rejeição dos alunos em relação à afirmação que trata da interdisciplinaridade na organização curricular em geral, e ainda $33 \%$ de rejeição no que diz respeito à contemplação de atividades complementares para a produção de conhecimentos pelo aluno.

Ainda, merecem atenção as opiniões sobre o dimensionamento adequado e satisfatório da carga horária entre as unidades de estudo ( $50 \%$ de rejeição). 0 mesmo é dito da afirmação que analisa se o PPP objetiva uma formação adequada do estudante, por meio da articulação entre ensino, pesquisa e extensão/assistência ( $47 \%$ de rejeição). 0 quadro continua o mesmo quando se fala de um egresso capaz de desenvolver, participar e aplicar formas de produção do conhecimento, objetivando a qualificação profissional (39\% de rejeição); da mesma forma, quando se fala de um formando capaz de compreender a política de saúde no contexto das políticas sociais, reconhecendo os perfis epidemiológicos das populações ( $47 \%$ de rejeição).

A análise geral da opinião dos discentes em relação aos objetivos, ao perfil do egresso e à organização didáticopedagógica do projeto político-pedagógico e do currículo revela que o curso de graduação em enfermagem da FAEN carrega em si o propósito de habilitar o enfermeiro para o SUS, embora o hiato separando a clínica e a epidemiologia, a saúde individual e coletiva, a formação técnico-científica, a ético-humanística e política, a teoria e a prática, comprometa a formação do egresso.

Desse modo, o conjunto dos resultados obtidos a partir da opinião dos discentes reflete que, apesar das boas intenções, as estratégias de implementação se mostraram frágeis para dar conta da concretização do ideal expresso no PPP. Ainda existe um abismo a ser superado entre o ideal do processo apresentam-se pistas de mudanças que podem contribuir para a orientação do processo de formação do enfermeiro com base em um novo perfil profissional, adequado e indispensável para a consolidação do SUS.

formativo e o que está sendo realmente efetivado; isso é agravado ainda mais pela falta de uma maior abertura dos serviços para com as propostas das instituições de educação em saúde, perpetuando a dicotomia ensino-trabalho.

Este exemplo particular apresenta uma dificuldade sentida na concretização de muitos projetos formativos de instituiç̃es de ensino superior. Os problemas a serem enfrentados e os ideais a serem atingidos são geralmente bem conhecidos. Os meios adequados para se chegar a tais fins, porém, constituemse nos maiores desafios. Fórmulas pré-definidas e caminhos únicos parecem não existir.

Entretanto, alguns elementos são essenciais na concretização das melhores intenções formativas, por mais diferentes que sejam os meios. Entre estes elementos, destacam-se a necessidade de participação efetiva e constante de todos os sujeitos aí envolvidos e a capacidade de adaptação das propostas dos diversos projetos às exigências da dinâmica da realidade. Talvez essas sejam as chaves de solução para os problemas indicados na avaliação dos discentes da FAEN/UERN.

\section{REFERÊNCIAS}

1. Pinheiro EFC, Lopes MLS, Ohira RHS, Nicoletto SCS. Profissional de saúde: a inter-relação entre formação e prática. Formação 2003 maio/ago; 3(8): 47-58.

2. Lei n. 9.394, de 20 de dezembro de 1996. Estabelece as diretrizes e bases da educação nacional. Diário Oficial da República Federativa do Brasil, Brasília (DF), 23 dez 1996: Seção 1.

3. Ministério da Educação (BR). Conselho Nacional de Educação. Câmara de Educação Superior. Resolução CNE/CES n 3, de 7 de novembro de 2001. Diretrizes curriculares nacionais do curso de graduação em enfermagem. Brasília (DF); 2001.

4. Rodrigues J, Zagonel IPS, Mantovani MF. Alternativas para prática docente no ensino superior de enfermagem. Esc Anna Nery Rev Enferm 2007 jun; 11(2): 313-17.

5. Marconi MA, Lakatos EM. Fundamentos de metodologia científica.

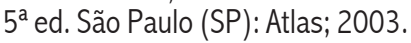

6. Richardson RJ. Pesquisa social: métodos e técnicas. São Paulo (SP): Atlas; 1999.

7. Ministério da Educação (BR). Comissão Nacional de Avaliação da Educação Superior. Instituto Nacional de Estudos e Pesquisas Educacionais Anísio Teixeira. Avaliação de cursos de graduaçãoinstrumento. Brasília (DF); 2006.

8. Seiffert OMLB. A formação do enfermeiro: uma aproximação à recente produção científica. Trab Educ Saude 2005; 3(2): 331-50.

9. Silva KL, Sena RR. A educação de enfermagem: buscando a formação crítico-reflexiva e as competências profissionais. Rev Latino-am Enfermagem [on-line] 2006 set/out; [citado 17 jun 2007]; 14(5): [aprox. 7 telas]. Disponível em: www.eerp.usp.br/rlae. 
10. Moretto EFS. Os enfermeiros e sua relação com os princípios do SUS. Texto\& Contexto Enferm 2000 maio/ago; 9(2): 611-20.

11. Feuerwerker LCM. Por que a cooperação com o SUS é indispensável para os cursos universitários na área da saúde. Olho Mágico 2006 jan/mar; 13(1): 32-8.

12. Silva JPV, Tavares MM. Integralidade: dispositivo para a formação crítica de profissionais de saúde. Trab Educ Saude 2004; 2(2): 27185.

13. Heyden MST, Resck ZMR, Gradim CVC. A pesquisa na graduação em enfermagem: requisito para conclusão do curso. Rev Bras Enferm 2003 jul/ago; 56(4): 409-11.

14. Palmeira IP, Rodriguéz MB. A investigação científica no curso de enfermagem: uma análise crítica. Esc Anna Nery Rev Enferm 2008 mar; 12(1): 68-75.
15. Barbosa MA, Medeiros M, Prado MA, Bachion MM, Brasil VV. Reflexões sobre o trabalho do enfermeiro em saúde coletiva. Rev Eletr Enferm 2006; 6(1): 09-15.

16. Pinto JBT, Pepe AM. A formação do enfermeiro: contradições e desafios à prática pedagógica. Rev Latino-am Enfermagem; [on- line] 2007 jan/fev; [citado 20 jun 2007]; 15(1): [aprox. 8 telas]. Disponível em: www.eerp.usp.br/rlae

17. Scherer ZAP, Scherer EA, Carvalho AMP. Reflexões sobre o ensino da enfermagem e os primeiros contatos do aluno com a profissão. Rev Latino-am Enfermagem 2006 mar/abr; 14(2): 285-91.

18. Rozendo CA, Casagrande, DLR, Schneider JF, Pardini LC. Uma análise das práticas docentes de professores universitários da área de saúde. Rev Latino-am Enfermagem 1999 abr; 7(2): 15-23.

\section{NOTAS}

a Artigo derivado da pesquisa de disser tação de mestrado apresentada ao Programa de Pós-Graduação em Enfermagem da Universidade Federal do Rio Grande do Norte, intitulada "A formação acadêmica do enfermeiro para o SUS na percepção de docentes e discentes da Faculdade de Enfermagem/UERN". 